\title{
BIODIVERSITY IN APPLE ORCHARDS: APPLE TREE FOLIAGE AND GROUND COVER SAMPLING
}

\author{
D.M. SUCKLING ${ }^{1}$, C.H. WEARING, A.R. GIBB ${ }^{1}$, G.M. BURNIP ${ }^{1}$, \\ B. ATTFIELD ${ }^{2}$ and K. COULHOUN ${ }^{2}$ \\ ${ }^{1}$ HortResearch, PO Box 51 , Lincoln \\ ${ }^{2}$ HortResearch, Clyde Research Orchard, RD 1 Alexandra
}

\begin{abstract}
Beating trays and pitfall traps were operated on five occasions in three apple orchard management systems (biological, integrated and conventional fruit production) in Canterbury and Central Otago. The aim was to determine the presence of differences in species composition and biodiversity, that could potentially be used as biological measures of sustainability. The Shannon-Weiner index was used to compare the faunas sampled under each treatment. Pitfall traps had higher numbers of species and Shannon-Weiner index values than foliage samples from beating trays. Foliage sampling indicated the highest biodiversity in the integrated and biological treatments, with the lowest in conventional fruit production treatments. Despite the detection of more species in the understorey by pitfall trapping, apple tree foliage sampling by beating trays appears to have a greater ability to detect the impact of different production practices on the apple orchard fauna. Similar trends were evident from an analysis of the predators alone, in both beating tray and pitfall traps, which would offer considerable cost savings over an analysis of the total fauna.
\end{abstract}

\section{A NEW SAMPLING TECHNIQUE FOR ESTIMATING THE POPULATION DENSITIES OF GREENHOUSE THRIPS}

\author{
K.J. FROUD
}

\section{HortResearch, Private Bag 92169, Auckland}

Greenhouse thrips is a pest of citrus, avocado and ornamentals in New Zealand. A new sampling method was used to quantify greenhouse thrips abundance over time. Fortnightly samples of leaves $(\mathrm{n} \approx 100)$ were collected from sites $10 \mathrm{~m}$ apart along an Acmena smithii hedge in Auckland. Samples were taken from a standardised height of $0.5 \mathrm{~m}-2.0 \mathrm{~m}$ and from $30 \mathrm{~cm}-1 \mathrm{~m}$ inside the hedge and stored in plastic bags at $2^{\circ} \mathrm{C}$ for up to three weeks. The leaves were individually brushed using a mite-brushing machine (Leedom Engineering, California) and the thrips collected into a large glass petri dish containing $70 \%$ ethanol. The samples were poured into a plankton counter where each thrips life stage (first instar, second instar, prepupae/pupae, adults) and total numbers were counted. The exact number of leaves and thrips per sample was averaged for the ten replicates to give mean thrips per 100 leaves for each life stage. No thrips were missed on the leaves and leaf brushing and thrips counting was fast and relatively easy. This leaf brushing method was an effective and accurate method for estimating the abundance of greenhouse thrips over time. 